Научная статья

УДК $81 ’ 37=512.31$

DOI: $10.18101 / 2305-459 X-2020-3-108-114$

\title{
БАЗОВЫЕ ЦЕННОСТИ БУРЯТ: ОСОБЕННОСТИ ТРАНСФОРМАЦИИ ПРИ БИЛИНГВИЗМЕ
}

\author{
(C) Дырхеева Галина Александровна \\ доктор филологических наук, профессор, главный научный сотрудник, \\ Институт монголоведения, буддологии и тибетологии СО РАН \\ Россия, 670047, г. Улан-Удэ, ул. Сахьяновой, 6 \\ an5dag1@mail.ru
}

Аннотация. Статья посвящена анализу системы ценностей бурятского этноса, особенностям их трансформации в условиях усиливающегося роста числа бурятско-русских билингвов, утраты бурятами родного языка. На основе данных свободного ассоциативного эксперимента, сопоставления с материалами по «Русскому ассоциативному словарю» делается попытка показать степень устойчивости ценностной системы бурят. Выявлены базовые компоненты бурятской языковой картины мира. Установлено, что пока сила влияния национального языкового кода достаточно высокая. Показано, что влияние русского языка преимущественно сказалось на отражении «реального» окружения. Установлено, что ассоциативные поля выделенного ядра языкового сознания бурят на бурятском и русском языках имеют как общие, так и специфические особенности, которые во многом определяются структурно-семантической спецификой языка, а также национальными различиями представления о мире.

Ключевые слова: базовые ценности; языковое сознание; ядро языкового сознания; бурятский язык; билингвы; ассоциативный эксперимент; реакции-реалии; реакции-персоналии.

\section{Для цитирования}

Дырхеева Г. А. Базовые ценности бурят: особенности трансформации при билингвизме // Вестник Бурятского государственного университета. Язык. Литература. Культура. 2020. Вып. 3. С. 108-114.

Сегодня проблема межкультурных коммуникаций признается наиболее актуальной в гуманитарных науках конца XX — начала XXI в., что объясняется расширением границ и информационных пространств в современном мире, активизацией интеграционных процессов. В то же время как реакция на эти процессы наблюдаются этнокультурная дифференциация, повышенный интерес к своей истории, культуре, возрождение религии, обычаев и традиций и, несомненно, интерес к изучению содержания системы ценностей того или иного народа. Таким образом, идет усиление влияния на указанные глобализационные процессы таких субъективных факторов, как оценка, настроение, чувства, эмоции, интенции и т. д., анализ и учет которых крайне необходимы при рассмотрении межнационального взаимодействия и в крайнем случае этнических конфликтов.

Поиск и анализ специфических ценностей своего народа важен для каждого человека, для определения не только своей идентичности, но и своего положения 
в отношениях между людьми. Исследование духовных основ бурят, проживающих во многих регионах не только России, но и мира, расселившихся на стыке буддизма, православия и шаманизма, представляет огромный интерес, т.к., как и у многих народов, в них заложен фундамент общечеловеческих устоев, философско-религиозных учений о мире, обществе, человеке, они представляют огромную картину ценностных абсолютов, качеств, передававшихся из поколения в поколение. Имеются многочисленные, в том числе и языковые, свидетельства ментальных качеств, характерных для бурят: привязанность к своим родным местам, своей семье, трудолюбие, запасливость, толерантность, гостеприимство, терпимость к другим народам и религиям, доброта, сострадание, отзывчивость, стремление к образованию, высокий художественный вкус, музыкальность. Несомненно, что ценились свои обычаи и традиции, нравственное здоровье и не поощрялись дурные качества и наклонности: безделье, пьянство, распутство.

В психолингвистике одним из основных направлений является изучение индивидуальных, а также коллективных ценностных представлений. «Концепт ценности представляется не каким-то отдельным образованием (его выделяют условно), а совокупностью этих коннотативных компонентов, составляющих ценностную картину мира. Ценностные представления — это отношения между «узлами» ценностной картины мира. Они действительно динамичны и ситуативны, они не выстраиваются в иерархию, но взаимодействуют, позволяя человеку сделать выбор на основе оценки объектов. Важнейшие «узлы» можно было бы назвать базовыми ценностями, число и набор которых относительно постоянен, хотя они не лишены культурных акцентуаций» [10, с. 125].

Работы последних лет показывают, что ценностная картина мира бурят также неоднократно рассматривалась исследователями Бурятии. В основном это работы философов, этнографов, социологов [см. $6 ; 1 ; 5]$.

Одной из первых традиционные ценности бурят рассмотрела этнопсихолог И. Э. Елаева в коллективной монографии «Ценности и символы национального самосознания в условиях изменяющегося общества» [2]. Материалом для ее исследования послужили бурятский героический эпос «Гэсэр» и бытовые сказки. Автор выделяет следующие компоненты системы ценностей бурят: 1) смысл бытия человека, характер отношения к жизни; 2) отношение к Родине; 3) через любовь к Родине - ценностное отношение к природе; 4) человек и отношение к нему; 5) институт почитания старших; 6) уважение к женщине; 7) семья; 8) почитание огня; 9) дети; 10) родственные связи; 11) отношение к красоте; 12) представления о трудовой деятельности; 13) представления об идеальном человеке, его чертах характера.

Очевидно, возникает вопрос, в каком виде традиционные ценности представлены сегодня, каким образом они проявляются в поведении и, в частности, в языке представителей современного бурятского этноса, прекрасно владеющего русским языком и постепенно теряющего родной бурятский язык?

В связи с этим в ходе изучения ядра языкового сознания бурят-билингвов, проведенного в результате ассоциативного эксперимента, была сделана попытка не только раскрыть содержание некоторых ценностных фрагментов бурятской языковой картины мира (человек, дом, друг, жизнь, и др.), но и выявить особен- 
ности изменения в структуре ценностных ориентаций, связанные как с социально-культурными трансформациями, так и с переходом на другой, русский, язык общения.

По мнению Т. Н. Ушаковой, «ядро языкового сознания осуществляет лингвистическую проекцию бытия человека, сохраняющуюся на протяжении его жизни, ориентирующую его в окружающей действительности и составляющую основу его языковой картины мира» $[9$, с. 16].

Итак, ядро языкового сознания - это единицы семантической сети, которые имеют наибольшее число связей с другими единицами данной семантической сети [4, с. 168]. Оно выявляется с помощью обратного ассоциативного словаря, в котором отражено количество вхождений слова в гнезда - слова-стимулы. Ядро языкового сознания бурят-билингвов представлено в таблице, где Б1 - реакции бурят на бурятском языке, Б2 - реакции бурят на русском языке, $\mathrm{P}$ - реакции русских (по данным Н. В. Уфимцевой [8]). Первая цифра в скобках - количество реакций-гнезд, в которых встретилось слово, вторая цифра - общая частота встречаемости слова (приведена сумма всех форм слова).

По нашим данным, в первой группе реакций-персоналий при общем совпадении самых частых слов человек и друг (по данным Н. В. Уфимцевой [8], в русском ЯС эти понятия также являются самыми важными) имеются достаточно существенные отличия. Так, можно отметить появление в русскоязычной группе личного местоимения я (мой, моя, мое), а также такого понятия, как Бог. И если я также входит в самую частотную группу по данным РАС [7], и его появление можно объяснить влиянием русского языка на бурятское языковое сознание, то выделение слова Бог, скорее всего, связано с тем, что среди слов-стимулов были заданы такие специфичные регионализмы, как дащан, сэржэм и Будда.

Необходимо сразу отметить ярко выраженную значимость родственных, семейных отношений для бурят, в группу персоналий на бурятском языке вошли практически все самые близкие люди: эжы 'мама', аба 'отец', эхэ 'мать', $Y^{x u-}$ бүYн 'ребенок, дитя', басаган 'дочь, девочка, девушка', хүбүYн 'сын, мальчик', Убгэн 'старик, старый'. Причем показателем важности для бурят родовых отношений является сохранение в русскоязычной группе слов мама, близкие и отец, которые отсутствуют как самые важные в русском языковом сознании. Число соответствий между зонами Б1 и Б2 составляет $69 \%$, а между Б2 и Р $-38 \%$. Интересно то, что для русскоязычного сознания бурят важным осталось значение багша 'учитель' Характерно также то, что, в отличие от русского языкового сознания, в двуязычном бурятском сознании, отсутствуют такие слова с пейоративной окраской, как дурак (занимающее, по данным РАС, третье место в списке русских реакций-реалий) и мужик.

В отличие от реакций-персоналий, реакции-реалии показывают значительную разницу между языковым сознанием бурят на родном и на русском языках, доля совпадений между Б1 и Б2 составляет всего $21 \%$, а между Б2 и Р $-57 \%$. При этом общими и, очевидно, самыми важными для всех трех выделенных групп являются дом и жизнь, занимающие первые позиции в языковом сознании многих народов. Причем в ядро Б1 вошли практически два понятия жизнь: наһан и байдал, являющиеся многозначными, что еще раз подтверждает существенную 
разницу между семантическими полями сравниваемых языков. Значимость жизни для бурят подтверждается отсутствием понятия смерть в ядре Б1 и Б2, которое входит в ядро языкового сознания русских. Эти данные, по нашему мнению, свидетельствуют о том, что, несмотря на изменения в этническом сознании бурят, в нем сохраняются определенные этнические константы. Жизнь является наиболее важной ценностью их традиционного мировоззрения.

Практически в зону Б1 вошли слова, отражающие основные человеческие потребности и ценности, для байдал 'состояния, жизни' бэе 'тела' человека необходимо, чтобы светило наран 'солнце', была эдеэн 'пища, еда', какие-то юумэн 'вещи, что-то' ${ }^{1}$ был гэр 'дом', нютаг 'родина' и хэрэг 'дело, нужда', или ажал 'работа', которая, кстати, нужна и русским, и бурятам. Самое же интересное то, что существенной разницей между зонами Б1, Б2 и Р, по нашему мнению, является вхождение в зону Б1 таких единиц ментальной субстанции, как һанаaн 'мысль, намерение', ухаан 'ум, разум', сэдьхэл 'мысль, думы, помыслы'. Это слова, через которые проявляется такое отношение бурят к окружающей действительности, как стремление к знанию, обучению, что также подтверждается вхождением в ядро языкового сознания бурят в данном поле слова ном 'книга', а в поле «персоналии» - багша 'учитель'. Вхождение слова наран 'солнце' в ядро ЯС скорее всего объясняется значимостью окружающей среды, природы для бурята-кочевника, солнце считается основным источником, хозяином тепла и света, по солнцу они ориентировались для организации ежедневного распорядка дня, быта и уклада жизни.

В целом же можно сказать, что анализ группы реакций-персоналий показывает близость языкового сознания бурят на родном и на русском языках, в отличие от группы реакций-реалий. Несмотря на то, что первые две позиции здесь совпадают во всех трех обследованных массивах (Б1, Б2 и Р), т. е. жизнь и дом являются наиболее значимыми понятиями как для русских, так и для бурят, значительное число реакций (любовь, день, мир, радость, деньги и др.) в группах Б1 и Б2 существенно различаются. То есть языковое сознание бурят на русском языке в «реальности» ближе к языковому сознанию русских. Линий, соединяющих близкие по содержанию слова-реакции между Б1 и Б2 в зоне «персоналии», больше, чем между Б2 и Р, а в зоне «реалии», наоборот, их больше между Б2 и Р.

Линий, соединяющих зоны Б1 и Б2, также больше в поле «оценки качества», доля совпадений около $47 \%$, а между Б2 и Р $-25 \%$, хотя здесь также необходимо учитывать структурно-семантические языковые особенности. Более подробно данная группа слов рассматривается в разделе о ценностном компоненте в ядре языкового сознания бурят-билингвов.

\footnotetext{
${ }^{1}$ Как и многие другие высокочастотные слова бурятского языка юумэн является многозначным и многофункциональным словом, участвующим в образовании различных фразеологизмов, часто замещает другие слова. Необходимо также заметить, что о значимости «вещи» в функционировании сознания пишет И. В. Журавлев [3, с. 20-31].
} 
Ядро языкового сознания бурят-билингвов и русских

\begin{tabular}{|c|c|c|c|}
\hline & Б 1 & 52 & $P$ \\
\hline Персоналии & $\begin{array}{l}\text { Хүн 'человек' (69/200) } \\
\text { Нүхэр 'товарищ, друг' (28/92) } \\
\text { Эжы 'мама' (17/79) } \\
\text { Үхибүун 'ребенок, дитя' (14/43) } \\
\text { Эхэ 'мать' (13/30) } \\
\text { Зон 'народ' (11/19) } \\
\text { Басаган 'дочь, девочка' (10/47) } \\
\text { Аба 'отец' (10/38) } \\
\text { Хүбуүн 'сын, мальчик' (10/24) } \\
\text { Багша 'учитель' (9/36) } \\
\text { Айлшан 'гость' (9/19) } \\
\text { Арад 'народ' (8/18) } \\
\text { Үбгэн 'старик' (8/17) }\end{array}$ & $\begin{array}{l}\text { Человек } \\
(24 / 113) \\
\text { Я (мой) } 16 / 29 \\
\text { Друг }(15 / 97) \\
\text { Мама }(11 / 21) \\
\text { Люди }(11 / 19) \\
\text { Народ }(9 / 15) \\
\text { Бог }(8 / 46) \\
\text { Близкие }(8 / 13) \\
\text { Отец }(7 / 16) \\
\text { Мужчина }(7 / 11) \\
\text { Дети }(6 / 10) \\
\text { Друзья }(6 / 11) \\
\text { Учитель }(5 / 7)\end{array}$ & $\begin{array}{l}\text { Человек } \\
\text { Друг } \\
\text { Дурак } \\
\text { Мужчина } \\
\text { Ребенок } \\
\text { Парень } \\
\text { Я } \\
\text { Женщина } \\
\text { Мальчик } \\
\text { Девушка } \\
\text { Мужик } \\
\text { Муж } \\
\text { Он }\end{array}$ \\
\hline Реалии & 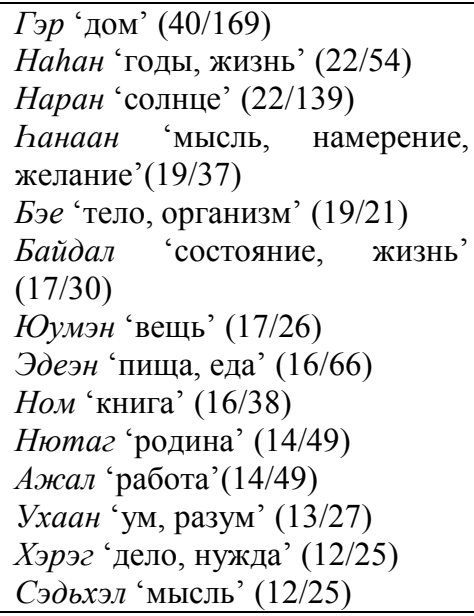 & $\begin{array}{l}\text { Жизнь }(33 / 65) \\
\text { Дом }(20 / 62) \\
\text { Работа }(13 / 57) \\
\text { Любовь }(13 / 28) \\
\text { Всё }(11 / 12) \\
\text { День }(11 / 27) \\
\text { Время }(11 / 16) \\
\text { Мир }(11 / 13) \\
\text { Радость }(10 / 28) \\
\text { Сила }(10 / 17) \\
\text { Чистота }(10 / 12) \\
\text { Правда }(8 / 69) \\
\text { Солнце }(8 / 36) \\
\text { Деньги }(7 / 31)\end{array}$ & $\begin{array}{l}\text { Дом } \\
\text { Жизнь } \\
\text { Деньги } \\
\text { Лес } \\
\text { День } \\
\text { Любовь } \\
\text { Работа } \\
\text { Вода } \\
\text { Радость } \\
\text { Дело } \\
\text { Смерть } \\
\text { Стол } \\
\text { Дорога } \\
\text { Мир }\end{array}$ \\
\hline $\begin{array}{l}\text { Оценки - } \\
\text { качества }\end{array}$ & 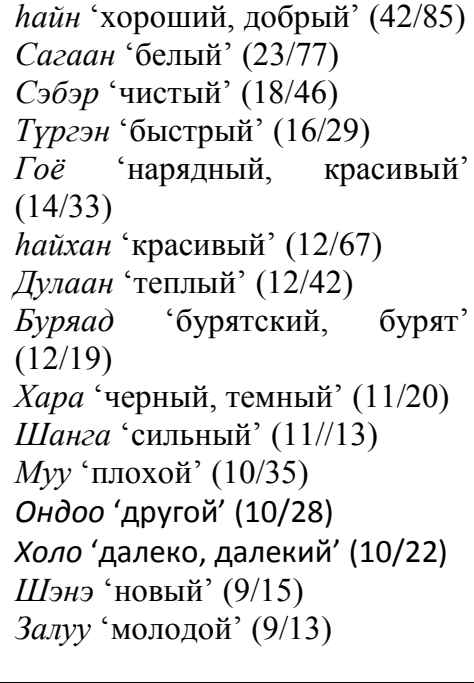 & $\begin{array}{l}\text { Хороший } \\
(20 / 56) \\
\text { Родной }(15 / 60) \\
\text { Добрый }(14 / 34) \\
\text { Любимый } \\
(14 / 33) \\
\text { Чистый }(13 / 35) \\
\text { Белый (11/61) } \\
\text { Большой } \\
(11 / 26) \\
\text { Новый }(11 / 18) \\
\text { Святой }(10 / 20) \\
\text { Светлый }(10 / 17) \\
\text { Старый }(9 / 18) \\
\text { Дорогой }(9 / 13) \\
\text { Красивый }(8 / 22) \\
\text { Вечный }(8 / 14)\end{array}$ & $\begin{array}{l}\text { Большой Хороший } \\
\text { Старый } \\
\text { Умный } \\
\text { Сильный } \\
\text { Мой } \\
\text { Плохой } \\
\text { Красный Белый } \\
\text { Зеленый } \\
\text { Маленький }\end{array}$ \\
\hline
\end{tabular}


Итак, можно сказать, что бурятские базовые лексические единицы, входящие в ядро языкового сознания, как и во многих языках, включают ограниченное число слов. Они несут важную культурологическую информацию, ценны для изучения национальной языковой картины мира, исследования образа мира того или иного этноса. По своему содержанию они очень разнообразны, так как включают в себя все параметры внутренних и внешних свойств и особенностей явлений природы, общества и человека. Именно ассоциативное поле человек, как и в других языках, является наиболее обширным и разнообразным, характеризующим человека как общественное существо. В результате проведенного эксперимента было также установлено, что ассоциативные поля выделенного ядра языкового сознания бурят на бурятском и русском языках имеют как общие, так и специфические особенности, которые во многом определяются структурно-семантической спецификой языка, а также национальными различиями представления о мире. Активное владение бурятами русским языком, а также окружающая действительность повлияли в основном на то, что именно в ассоциативном поле «реалии» произошло значительное число совпадений между ассоциациями бурят на русском языке и носителями русского языка, судя по PAC.

Таким образом, подтвердилось, что ценностная ориентация - ключевой компонент национальной картины мира, национального характера. Сравнение языкового сознания бурят в условиях бурятско-русского двуязычия, представленные ассоциативные реакции бурят на русском и бурятском языках показали, что ценностная картина мира бурят обладает устойчивостью. Наиболее устойчивыми традиционными ценностными компонентами в языковой картине мира бурят оказались: защита семьи, здоровье, настоящая дружба, верность, интеллект, смысл жизни, внутренняя гармония. Их можно отнести к базовым ценностям бурятской культуры, транслирующимся из поколения в поколение.

Несомненно, что иноязычное влияние способствуют изменению лексического состава и коммуникативных норм бурятского языка, оно трансформирует его культурную и ценностную систему, но в первую очередь в области «реального» отражения мира. Национально-культурное своеобразие бурятского языкового сознания сохраняется, в частности оно более миролюбивое, менее агрессивное. Открытость и доброжелательность бурятского этноса определяется, например, тем, что наиболее частыми оценочными словами-реакциями на бурятском языке являются слова с положительной коннотацией: hайн 'хороший, добрый' (23), сэбэр 'чистый' (16), хүнэй 'человеческий' (15), сагаан 'белый' (11). Причем реакция hайн 'хороший, добрый' по частоте даже превышает реакцию слова хүн 'человек'.

\section{Лumepamypa}

1. Дашибалова И. Н. Проблемы этнической стереотипизации бурят в ценностном аспекте. Улан-Удэ: Изд-во БНЦ СО РАН, 2006. 78 с.

2. Елаева И. Э. Традиционные ценности и этническое самосознание бурят // Ценности и символы национального самосознания в условиях изменяющегося общества. М., 1994. С. $184-216$.

3. Журавлев И. В. Движение вокруг вещи (к вопросу о природе сознания) // Язык. Сознание. Культура: сб. ст. / под ред. Н. В. Уфимцевой, Т. Н. Ушаковой. М.; Калуга: ИП Кошелев А. Б.; Эйдос, 2005. С. 20-31. 
4. Залевская А. А. Введение в психолингвистику. М.: Рос. гос. гуманит. ун-т, 1999. $382 \mathrm{c}$.

5. Лыгденова В. В. Трансформация традиционных ценностей баргузинских бурят в конце XX - начале XXI века [Электронный ресурс] // Новые исследования Тувы. 2014, № 3. URL: https://www.tuva.asia/journal/issue_23/7338-lygdenova.html (дата обращения: 10.10.20).

6. Осинский И. И. Традиционные ценности в духовной культуре бурятской национальной интеллигенции // Социс. 2001. № 3. С. 80-84.

7. Русский ассоциативный словарь. Кн. 3. Прямой словарь: от стимула к реакции. Ассоциативный тезаурус современного русского языка / Ю. Н. Караулов [и др.]. М.: ИРЯ РАН, 1996. Ч. II . 212 c.

8. Уфимцева Н. В. Образ мира русских: системность и содержание // Язык и культура. 2009. № 4. C. $98-111$.

9. Ушакова Т. Н. Языковое сознание и принципы его исследования // Языковое сознание и образ мира: сб. ст. / отв. ред. Н. В. Уфимцева. М., 2000. С. 13-23.

10. Федосюткина Н. С. Психолингвистический подход к изучению ценностных представлений// Вопросы психолингвистики. 2006. № 3. С. 114-126.

\section{BURYAT BASIC VALUES: \\ FEATURES OF TRANSFORMATION IN BILINGUALISM}

Galina A. Dyrkheeva

Dr. Sci. (Phil.), Chief Researcher,

Institute of Mongol, Buddist and Tibetan Studies of SB RAS

6 Sakhyanovoy St., 670047 Ulan-Ude, Russia

an5dag1@mail.ru

Abstract. Article is devoted to the analysis of a system of values of the Buryat ethnos, features of their transformation in the conditions of the amplifying growth of number of the Buryat-Russian bilinguals, loss by Buryats of their native language. On the basis of data of a free associative experiment, comparison to materials of "The Buryat associative dictionary", the attempt to show degree of stability of a Buryat valuable system becomes. Basic components of the Buryat language picture of the world are revealed. It is established that so far force of influence of the national language code is rather high. It is shown that influence of Russian mainly affected reflection of a "real" environment. It is established that associative fields of the allocated kernel of language consciousness in the Buryat and Russian languages have as the general and specific features which in many respects are defined by structuralsemantic specifics of language and also national distinctions of idea of the world.

Keywords: basic values language awareness; kernel of language consciousness; Buryat language; bilinguals; associative experiment; reactions realities; reactions personnel.

Статья поступила в редакичю 26.10.2020; одобрена после рещензирования 13.11.2020; принята к публикации 01.12.2020. 